\title{
KHẢ NĂNG ỨNG DỤNG MÔ HÌNH CYBER CITY TRONG CÔNG TÁC QUY HOẠCH ĐÔ TH!
}

\author{
ThS. MAI VĂN SỸ (1), TS. BÙI NGOC QUÝ(2) \\ PGS. TS. NGUYẾN TRƯỜ'NG XUÂN ${ }^{(2)}$ \\ (1)Công ty cổ phần tư vấn thiết kế công trình xây dựng Hải Phòng \\ (2) Trường Đại học Mỏ - Địa chất
}

\section{Tóm tắt:}

Trong công tác quy hoạch đô thị nhiều mô hình bản đồ đã được ứng dụng và mang lại hiệu quả cao như: bản đồ $2 D$, bản đồ $3 D$, sa bàn,...Tuy nhiên các mô hình này đều gặp phải các khó khăn nhất định trong việc thiết kế các phương án quy hoạch bởi đây đều là các mô hình tĩnh không có tính linh động. Mô hình Cyber City hay còn gọi là thành phố ảo sẽ khắc phục được những nhược điểm này. Việc triển khai xây dựng mô hình Cyber city (thành phố ảo) cho một thành phố hoặc vùng lãnh thổ không chỉ biểu thị các yếu tố và các thuộc tính của đối tượng mà nó còn có những chức năng như một thành phố thực sự trong môi trường ảo. Quan trọng hơn, nó cũng có thể xây dựng và phát triển theo những quan điểm chủ quan hoặc khách quan của những người thiết kế và xây dựng chúng theo những định hướng quy hoạch đã đề ra.Bài báo đề cập tới vấn đề nghiên cứu, xây dựng mô hình Cyber City hỗ trợ cho công tác quy hoạch đô thị.

\section{1. Đặt vấn đề}

Ngay từ khi mới ra đời Bản đồ luôn hướng tới một mục đích cơ bản là mô hình hóa các hình ảnh của bề mặt trái đất lên mặt phẳng. Trải qua quá trình lịch sử phát triển và xây dựng, ngày nay ngành bản đồ kết hợp với công nghệ thông tin đã và đang hướng tới mục tiêu quan trọng là mô hình hóa bề mặt càng gần với thực tế càng tốt. Chính vì thế, nhiều mô hình địa hình đã được nghiên cứu, xây dựng và đã trở thành một phương tiện thông tin với đầy đủ các chức năng để mô hình hoá, phân tích không gian và tái tạo thực tế.

Ở nhiều nước trên thế giới, việc ứng dụng các thành tựu của công nghệ tin học vào lĩnh vực bản đồ, đặc biệt là hệ thống thông tin địa lý (GIS) rất phát triển, nên việc xây dựng các mô hình Cyber City để mô hình hóa và quy hoạch lãnh thổ đã trở thành một phương pháp hiện đại.

Ở Việt Nam cũng đã sớm áp dụng bản đồ số và các công nghệ tin học, GIS,...để thành lập các mô hình này, tuy nhiên do khối lượng công việc lớn, nhiều vấn đề kỹ thuật và chuẩn dữ liệu chưa được thống nhất nên đến nay việc triển khai xây dựng các mô hình Cyber City vẫn còn chưa được quan tâm nghiên cứu nhiều. Đặc biệt là việc nghiên cứu một cách có hệ thống và đưa ra cơ sở khoa học và quy trình trong xây dựng các mô hình Cyber City vẫn chưa được quan tâm.

Có thể nói, Cyber City là mô hình ảo của một thành phố hoặc vùng lãnh thổ trong một hệ thống thông tin hỗ trợ một cách hiệu quả cho việc quy hoạch, thiết kế, xây dựng, quản lý và nhiều ứng dụng khác [6].

Việc triển khai xây dựng mô hình Cyber City cho một thành phố hoặc vùng lãnh thổ không chỉ biểu thị các yếu tố và các thuộc tính của đối tượng mà nó còn có những chức năng của một thành phố thực sự. Quan trọng hơn, nó cũng có thể xây dựng và phát triển theo những quan điểm chủ 
quan hoặc khách quan của những người thiết kế và xây dựng chúng theo những định hướng quy hoạch đã đề ra.

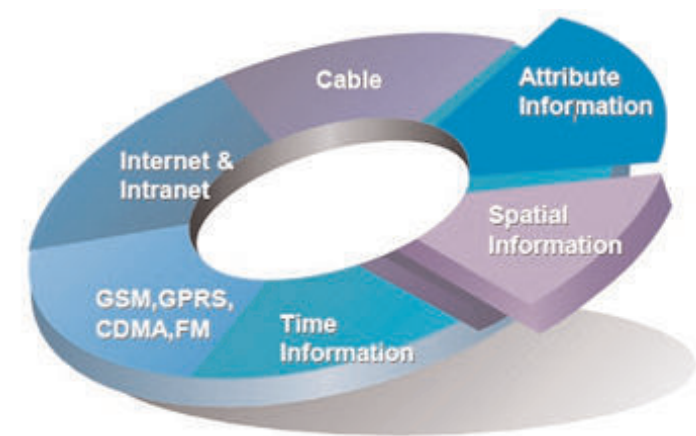

Hình 1: Nội dung của mô hình Cyber city [6]

\section{Vai trò của mô hình 3D trong công tác mô hình hóa bề mặt và định hướng quy hoạch không gian}

\subsection{Trên thế giới}

Mô hình 3D ứng dụng trong công tác mô hình hóa bề mặt và định hướng quy hoạch không gian đã được quan tâm nghiên cứu ở nhiều nước trên thế giới như Úc, Nhật, Đức, Anh, Trung Quốc, Đài Loan,...[3, 4, 5, 6, 7, 8]. Ngay từ thời kỳ đầu của lịch sử phát triển bản đồ học, các nhà bản đồ đã tìm ra nhiều phương pháp mô hình hóa bề mặt Trái đất lên mặt phẳng bản đồ.Với các mô hình 3D các nhà bản đồ học đã mô hình hóa bề mặt lãnh thổ một cách trực quan, sinh động giúp cho quá trình nhận thức về lãnh thổ nhanh hơn, trực quan hơn. Các mô hình 3D đã được sử dụng trong nhiều lĩnh vực khác nhau như: thủy văn, giao thông, quy hoạch, quân sự, ...[1, 2, 8, 9]. Đặc biệt, ý tưởng ứng dụng công nghệ 3D là trong công tác quy hoạch đã được Saarinen đưa ra từ nửa đầu thế kỷ 20 [10]. Tuy nhiên, chỉ đến khi công nghệ tin học phát triển thì việc hiện thực hóa ý tưởng của Saarinen mới có thể thực hiện được [11, 12, 13].

Sự phát triển mạnh mẽ của công nghệ đã làm thay đổi nhanh chóng các phương pháp mô hình hóa bề mặt và ứng dụng của nó. Với sự trợ giúp của công nghệ tin học các hệ thống 3D GIS đã được nghiên cứu, xây dựng và phát triển. Các hệ thống $3 \mathrm{D}$ GIS này thường mô hình hóa bề mặt lãnh thổ thông qua DEM (Digital Elevation Model) kết hợp với các ký hiệu mô phỏng đối tượng trên bề mặt Trái đất với các cấp độ chi tiết khác nhau đã làm cho việc ứng dụng $3 \mathrm{D}$ GIS trong công tác quy hoạch ngày càng trở lên phổ biến hơn. Đặc biệt, sự phát triển mạnh mẽ của công nghệ tin học đã tạo ra những bước đột phá trong công tác quy hoạch, việc triển khai xây dựng các hệ thống Cyber City (thành phố ảo) hay Smart City (thành phố thông minh) đã và đang được nghiên cứu và ứng dụng trong công tác quy hoạch của nhiều nước trên thế giới $[2,5,6,7,14,15]$.

Hiện nay, trên thế giới các nghiên cứu về Cyber City phục vụ cho công tác mô hình hóa bề mặt và định hướng trong quy hoạch không gian đã và đang được đầu tư nghiên cứu và phát triển. Các mô hình Cyber city được xây dựng là kết quả của quá trình tích hợp nhiều loại dữ liệu khác nhau như: DEM, ảnh vệ tinh, bản đồ địa hình, ảnh số, dữ liệu lidar,... để tạo ra mô hình thành phố ảo có tính trực quan cao từ đó giúp cho các cán bộ quy hoạch có được những cảm nhận tốt hơn, trực quan hơn về không gian và mối quan hệ giữa các thực thể địa lý trong khu vực. Thông qua mô hình Cyber City này các cán bộ quy hoạch sẽ thực hiện xây dựng các kịch bản quy hoạch cho bề mặt lãnh thổ và xác định tính ưu việt của từng kịch bản từ đó hỗ trợ cho quá trình ra các quyết định quy hoạch một cách chính xác và đạt hiệu quả kinh tế cao [6].

\section{2. Ở Việt Nam}

Ở Việt Nam, công tác mô hình hóa bề mặt đã được các nhà bản đồ học quan tâm và nghiên cứu ngay từ thời kỳ đầu phát triển của ngành khoa học này. Từ các bản đồ phẳng cho đến các bản đồ $3 \mathrm{D}$ và đến nay là các hệ thống 3D GIS. Cùng với sự phát triển khoa học kỹ thuật và tiếp cận các công nghệ 
tiên tiến trên thế giới các tổ chức và cá nhân cũng đã và đang tiến hành triển khai xây dựng các thể loại bản đồ $3 \mathrm{D}$ phục vụ cho các mục đích của mình $[16,27]$. Các mô hình $3 \mathrm{D}$ cũng được triển khai và nghiên cứu trong nhiều lĩnh vực khác nhau như quân sự, giáo dục, du lịch, viễn thông, hàng không, quy hoạch, ....[23, 24, 25].

Công nghệ GIS đã được ứng dụng trong công tác quy hoạch ở nước ta từ những năm cuối của thế kỷ 20 [18]. Một số công trình nghiên cứu, ứng dụng GIS trong công tác quy hoạch cũng đã được tiến hành triển khai theo những khía cạnh khác nhau và đã được áp dụng thí điểm cho 1 số tỉnh, thành phố như Hà Nội, Đà Lạt, Hạ Long, ...[19,20]. Ngày nay, công tác nghiên cứu và ứng dụng mô hình $3 \mathrm{D}$ trong quy hoạch ngày càng được nhiều người làm quy hoạch quan tâm nghiên cứu. Cùng với sự phát triển của công nghệ tin học, công nghệ GIS đã tạo ra một công nghệ mới (công nghệ 3D GIS) hỗ trợ cho lĩnh vực quy hoạch không gian $[22,23,24,25,26]$. Đối với các dạng 3D GIS hiện nay chủ yếu được xây dựng trên các phần mềm GIS như 3D Studio Max Design; ArcSence, City Engine của hãng ESRI (Mỹ), Skyline,...[16,25,27]. Mặc dù đã được 1 số cơ quan, đơn vị nghiên cứu, tuy nhiên các công trình nghiên cứu về $3 \mathrm{D}$ GIS cho công tác mô hình hóa bề mặt và định hướng quy hoạch không gian ở nước ta vẫn còn mang tính nhỏ lẻ chưa được thực hiện nhiều, dữ liệu còn thô sơ, chưa đi sâu vào mô hình hóa chi tiết các đối tượng trên bề mặt,...[21, 26]. Đặc biệt, chưa triển khai xây dựng mô hình Cyber City (thành phố ảo) phục vụ cho công tác định hướng quy hoạch không gian, các khái niệm về mô hình Cyber City mới được một số nhà khoa học tiếp cận tại các hội thảo khoa học quốc tế.

Có thể nói, Cyber City là mô hình ảo của một thành phố hoặc vùng lãnh thổ trong một hệ thống thông tin hỗ trợ một cách hiệu quả cho việc quy hoạch, thiết kế, xây dựng, quản lý và nhiều ứng dụng khác. Việc triển khai xây dựng mô hình Cyber City cho một thành phố hoặc vùng lãnh thổ không chỉ biểu thị các yếu tố bề mặt lãnh thổ và các thuộc tính của đối tượng mà nó còn có những chức năng của một thành phố thực sự. Quan trọng hơn, nó cũng có thể xây dựng và phát triển theo những quan điểm chủ quan hoăc khách quan của những người thiết kế và xây dựng chúng theo những định hướng quy hoạch đã đề ra. Vì vậy, nhằm nâng cao hiệu quả khai thác CSDL trong công tác giám sát, quản lý và định hướng chiến lược trong công tác quy hoạch không gian, tạo lập một mô hình không chỉ mang đầy đủ nguồn thông tin chiều sâu phục vụ các bài toán phân tích CSDL mà nó còn cho phép chúng ta có cái nhìn trực quan, tổng thể về bề mặt lãnh thổ, cũng như mối liên hệ hữu cơ giữa các yếu tố liên quan có sự biến đổi phức tạp như thiên tai, các sự cố môi trường do chịu sự ảnh hưởng trực tiếp của biến đổi khí hậu...đối với công tác quy hoạch không gian. Do đó việc triển khai xây dựng các mô hình Cyber City có ý nghĩa khoa học và thực tiễn cao, đặc biệt là trong công tác mô hình hóa bề mặt và định hướng quy hoạch không gian.

\section{Thử nghiệm xây dựng mô hình Cyber City}

Để chứng minh vai trò của mô hình Cyber City trong công tác mô hình hóa bề mặt và định hướng quy hoạch chúng tôi đã triển khai xây dựng thực nghiệm mô hình Cyber City cho khu chung cư The Manor, Mễ Trì, Nam Từ Liêm, thành phố Hà Nội.

Mô hình hoàn thiện đã mô phỏng được bề mặt khu vực ở cấp độ chi tiết LoD5 (Level of Detail) với độ chi tiết rất cao: (Xem hinh 2, 3) 


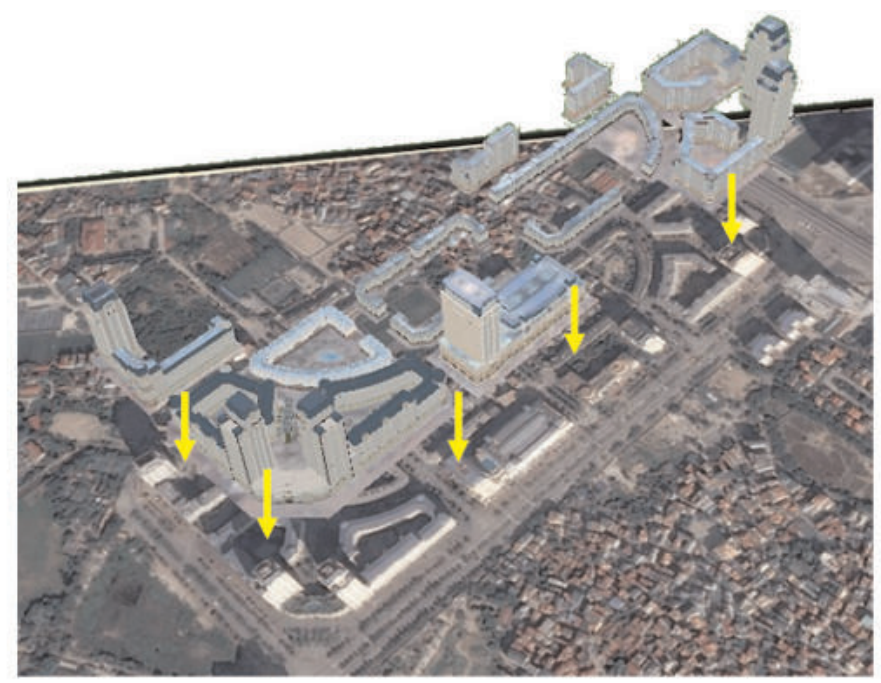

Hình 2: Đưa các đối tượng 3D lên mô hình
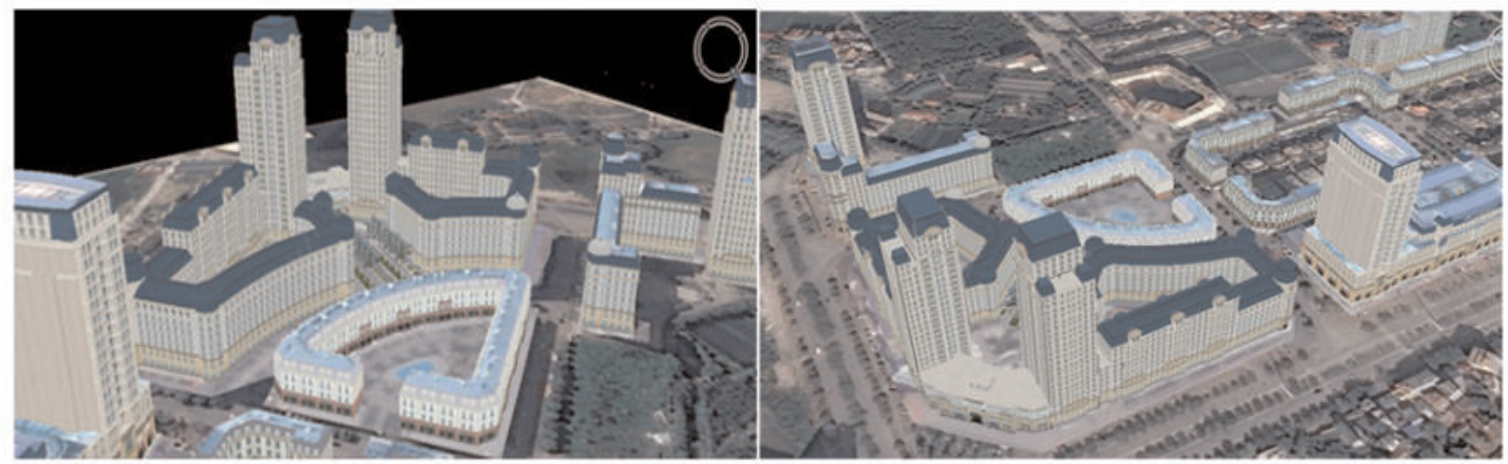

Hình 3: Mô hình Cyber City với nhiều góc nhìn khác nhau

3.1. Khả năng ứng dụng mô hình Cyber City trong định hướng quy hoạch đô thị

Mô hình Cyber City hoàn thiện sẽ cho phép quan sát khu vực tổng thể các đối tượng trên mặt đất như nhà cửa và các công trình xây dựng một cách trực quan từ nhiều phía khác nhau.

Cho phép thực hiện các phép đo đạc khoảng cách, kích thước và độ cao của các đối tượng trên ngay trên mô hình Cyber City. Tính năng này cho phép người sử dụng, đặc biệt là các nhà thiết kế, nhà quy hoạch có thể nắm bắt các đặc điểm về không gian của khu vực một cách đầy đủ nhất và có thể phác thảo các phương án thiết kế trên mô hình.

Có khả năng ứng dụng trong:

- Quản lý cơ sở hạ tầng như giao thông vận tải: Mở rộng, nâng cấp, thay thế, đổi tên đường;

- Quản lý phục vụ quy hoạch không gian: Sự sắp đặt của đối tượng, ảnh hưởng của ánh sáng, diện tích để xây dựng đối tượng;

- Quản lý công trình xây dựng: Phá bỏ công trình, xây mới các công trình;

- Quản lý hệ thống dẫn nước, đường ống dẫn nước, điện lực,.... 
Mô hình Cyber City có tính trực quan cao nên có thể ứng dụng rất tốt trong các tình huống cứu trợ khẩn cấp, hoặc cứu hỏa, xác định các tuyến đường tối ưu, quy hoạch và quản lý đô thị,... (Xem hình 4)

3.2. Thử nghiệm một số phương án quy hoạch trên mô hình Cyber City của khu vực nghiên cứu

Với mô hình Cyber City đã xây dựng ta có thể thực hiện các thao tác trên mô hình ảo để đưa ra các phương án xem có phù hợp với đặc điểm của khu vực hay không? Một số thao tác có thể thực hiện trên mô hình như: đo đạc phục vụ thiết kế, phân tích tầm nhìn, mô phỏng các phương án quy hoạch,...

\subsection{1. Đo đạc dũ̃ liệu phục vụ công tác thiết kế}

Trên mô hình Cyber City chúng ta có thể thực hiện các công tác đo đạc như: đo khoảng cách, chiều cao, diện tích,...của các đối tượng. Với các kết quả đo đạc trên mô hình ảo chúng ta có thể thu nhận được các thông tin phục vụ cho công tác thiết kế và quy hoạch các

3.2.2. Phân tích tầm nhìn dọc theo một con đường
Khả năng mở rộng Viewshed cho phép ta xác định những khu vực có thể nhìn thấy từ bất kỳ điểm nào chọn cùng một tuyến đường. Chúng ta có thể xác định chiều cao và bán kính khi phân tích viewshed. Khi di chuyển trên các tuyến đường thì thuộc tính viewshed có thể được hiển thị như:

+ Kết quả hiển thị tầm nhìn tại mỗi vị trí khi phương tiện di chuyển dọc theo tuyến đường

+ Có thể xây dựng phạm vi tầm nhìn từ bất cứ vị trí hoặc tuyến di chuyển nào trong mô hình từ đó có thể xây dựng các vị trí tối ưu trong công tác thiết kế và lắp đặt các hệ thống giám sát từ xa,.v.v...

\subsubsection{Thiết kế mô phỏng các phương án xây dụ̂ng trên mô hình ảo}

Khi triển khai xây dựng các phương án xây dựng bổ sung hoặc phá dỡ hoàn toàn để xây mới, chúng ta có thể sử dụng mô hình Cyber City để tạo dựng các phương án và phân tích các mặt ưu nhược điểm của phương án để đánh giá mức độ ảnh hưởng của nó tới khu vực, chẳng hạn như:

- Ảnh hưởng của công tác phá bỏ công trình cũ đến cảnh quan của khu vực như:

+ Phá nhà cửa, công trình gây ra tiếng

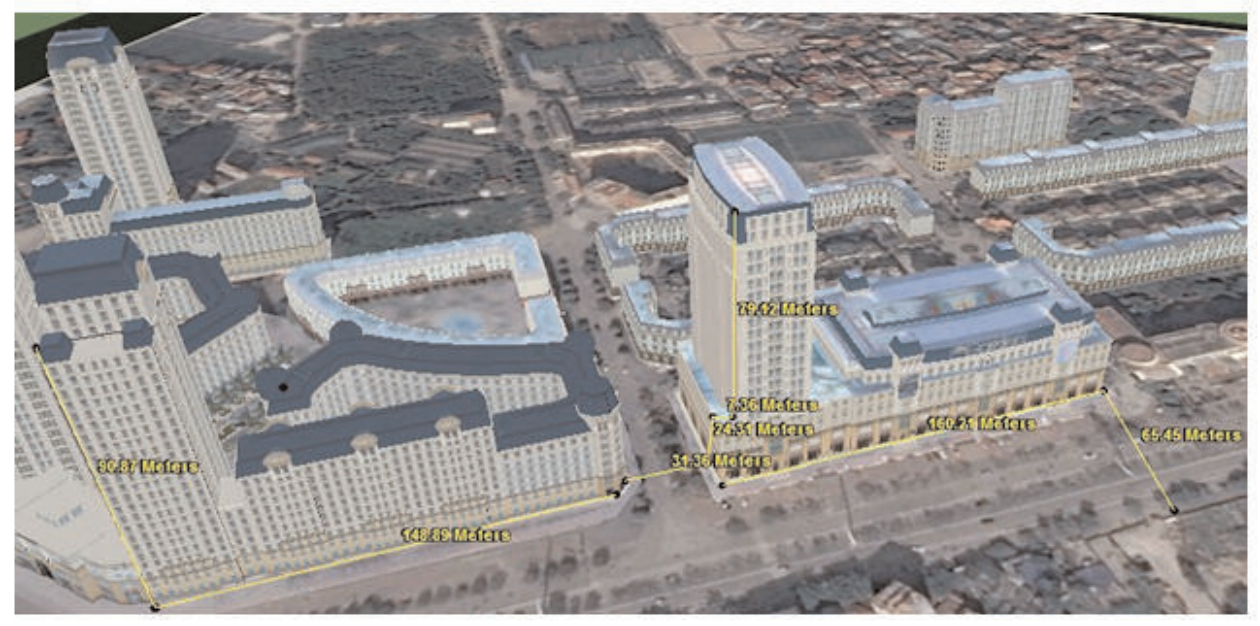

Hình 4: Công tác đo đạc phục vụ phác thảo quy hoạch trên mô hình 
ồn, bụi bẩn ảnh hưởng tới môi trường cảnh quan xung quanh khu vực chung cư cao cấp The Manor.

+ Chặt cây cối, đào bới khu vực xây dựng phá huỷ cảnh quan của đô thị.

+ Quá trình vận chuyển các nguyên liệu của phá dỡ công trình ảnh hưởng tới môi trường đô thị, gây ra bụi bẩn, ô nhiễm môi trường, đổ thải vật liệu xây dựng bừa bãi sẽ ảnh hưởng tới môi trường....(Xem hình 5)

\subsubsection{Phân tích khả năng chiếu sáng} của mặt trời theo thời gian thực cho mô hình đô thị trên mô hình ảo

Bóng chiếu sáng từ mặt trời cho phép ta tạo ra những hình ảnh thực tế hơn bằng cách tự động tạo bóng từ tất cả các mô hình

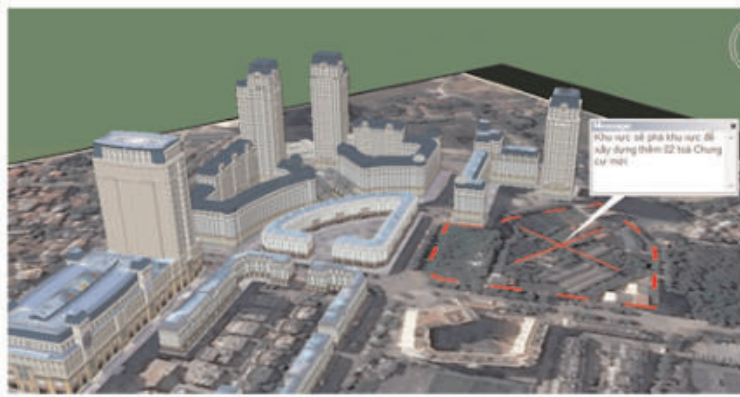

a
3D trong một lớp. Bóng của các tòa nhà và các đối tượng có độ cao thực trên bề mặt tự động cập nhật khi hệ thống ngày và thời gian được thay đổi.

Các công trình xây dựng lớn luôn ảnh hưởng tới khoảng không gian, tầm nhìn, ánh sáng .v.v... tới các khu vực lân cận. Với mô hình Cyber City chúng ta có thể sử dụng các chức năng phân tích trên mô hình để đánh giá và dự báo khả năng ảnh hưởng chiếu sáng đến khu vực để từ đó có thể đưa ra được quy mô, phạm vi thiết kế xây dựng cũng như lựa chọn phương án tối ưu nhất chon việc chọn hướng và thiết kế để các vị trí trong toàn bộ tòa nhà cũng như toàn khu vực nhận được ánh sáng mặt trời nhiều nhất. (Xem hình 6)

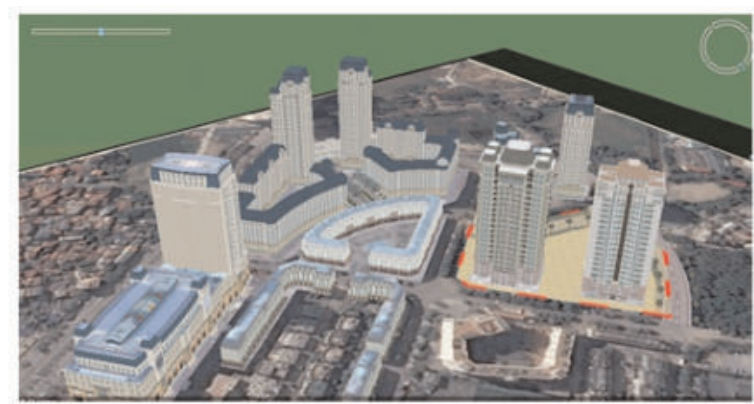

b

Hình 5: Hình ảnh khu vực trước (a) và sau (b) khi quy hoạch xây dụ̂ng mới

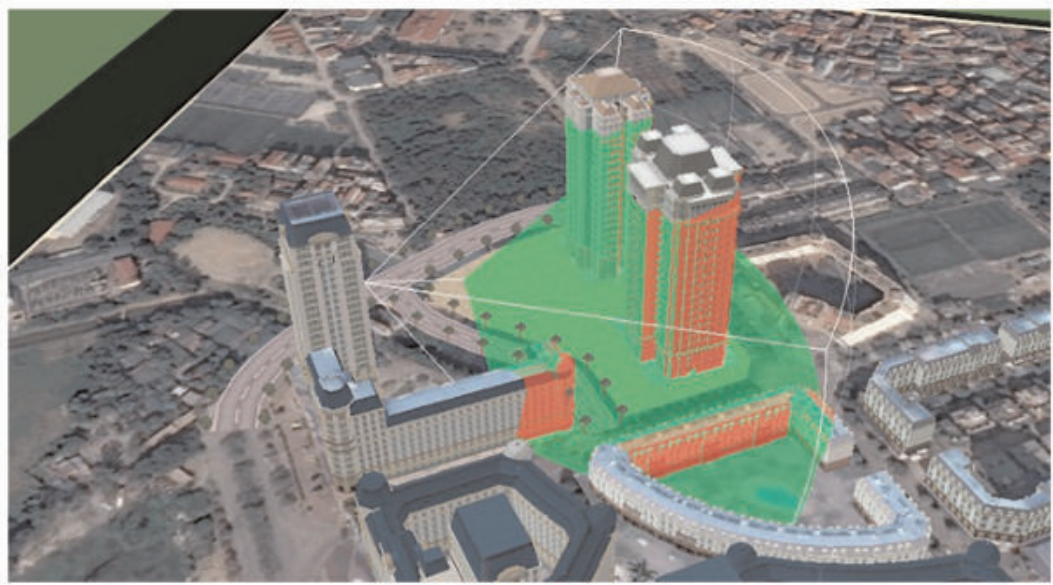

Hình 6: Tính toán ảnh hưởng tới tầm nhin, ánh sáng của khu vực 


\section{Kết luận}

Có thể nói việc ứng dụng GIS trong công tác thiết kế đô thị phục vụ quy hoạch xây dựng là một hướng nghiên cứu có tính ứng dụng cao trong thực tể. Tuy nhiên, đây cũng là một vấn đề rất rộng và khá phức tạp do đặc thù việc quản lý của ngành xây dựng là rất đa dạng, rộng lớn và dữ liệu được thu thập qua nhiều năm trong khi quá trình đô thị hóa đang diễn ra nhanh chóng. Chính vì vậy, để có thể hoàn chỉnh các thiết kế đô thị phục vụ quy hoạch xây dựng là một công việc đòi hỏi nhiều thời gian và kinh nghiệm.

Việc nghiên cứu và tiếp cận xây dựng mô hình Cyber City sẽ là một công cụ hữu hiệu trong công tác quy hoạch không gian đô thị. Mô hình Cyber City có khả năng cung cấp cho các nhà quản lý xây dựng, các nhà quy hoạch,... một cái nhìn tổng thể trong không gian 3 chiều về bề mặt khu vực một cách trực quan, hơn thế nữa nó còn có khả năng tạo ra các kịch bản trong không gian ảo để đánh giá được mức độ ảnh hưởng của các công trình đối với địa bàn nghiên cứu. Chính vì thế việc triển khai nghiên cứu và ứng dụng mô hình Cyber City trong công tác quy hoạch không gian đô thị sẽ mang lại hiệu quả kinh tế cao.

Trong tương lai gần, với sự phát triển mạnh mẽ của các thiết bị phần cứng thì việc hiển thị các mô hình $3 \mathrm{D}$ nói chung và mô hình Cyber City nói riêng sẽ không còn khó khăn nữa. $O$

\section{Tài liệu tham khảo}

[1]. G Drogue, L Pfister, T Leviandier, J Humbert, L Hoffmann, A El Idrissi, J.-F Iffly, "Using 3D dynamic cartography and hydrological modelling for linear streamflow mapping", Computers \& Geosciences, Volume 28, Issue 8, October 2002, Pages 981-994

[2]. Gerhard Gröger, Lutz Plümer, "Topology of surfaces modelling bridges and tunnels in 3D-GIS", Computers,
Environment and Urban Systems, Volume 35, Issue 3, May 2011, Pages 208-216.

[3]. Zhao Zhongyuan, "Research on 3D Digital Map System and Key Technology" Procedia Environmental Sciences, Volume 12, Part A, 2012, Pages 514-520, 2011 International Conference of Environmental Science and Engineering.

[4]. Siyka Zlatanova, Alias Abdul Rahman, Morakot Pilouk, "Trends in 3D GIS development", Journal of Geospatial Engineering, Vol. 4, No. 2 (December, 2002), pp.1-10.

[5]. Masahiko Murata, "3D-GIS Application for Urban Planning based on 3D City Model", PASCO Corporation, Tokyo, Japan

[6]. Fuan Tsai, "Cyber City Implementation, Visualization and applications", Center for Space and Remote Sensing Research, National University Central, Taiwan, 2013.

[7]. MAO Wei-qing, Study on the Construction and Application of 3D Geographic Information services for the Smart City", ISPRS Annals of the Photogrammetry, Remote Sensing and Spatial Information Sciences, Volume II-4, 2014, ISPRS Technical Commission IV Symposium, 14 - 16 May 2014, Suzhou, China.

[8]. Siyka Zlatanova, "3D GIS for Urban Development ", PhD thesis, Enschede, ITC, The Netherlands.

[9]. http://www.geoweb3d.com/solutions/defense/ (Geoweb 3D - Advancing Visualization, "Rapid and Accurate 3D visualization and analysis for defense solutions")

[10]. Eliel Saarinen, "The city, its growth, its decay, its future", Massachussetts Institute of Technology Press paperback 
series, 1943.

[11]. Dodge, M., S. Doyle, A. Smith and S. Fleetwood, 1998, Towards the virtual city: VR\&Internet GIS for urban planning, in: Virtual Reality and Geographical Information Systems Workshop, 22nd May 1998, Birkbeck College, London, 12 p.

[12]. IGG, University of Rostock, 1999, 3D Geo-information systems for urban planning and design, http://www.agr.uni-rostock.de/gg/cebit_e/

[13]. Zhang Xia, Zhu Qing, "Applications of 3D City models based spatial analysis to Urban design", ISPRS Conggress, Processdings of Commission WG II/6. Istanbul, 2004.

[14]. Leonidas G. Anthopoulos, and Athena Vakali, "Urban Planning and Smart Cities: Interrelations and Reciprocities" (c) Springer-Verlag Berlin Heidelberg 2011.

[15]. S.P. Sekar, "Marching Towards Cyber City - A Planning Perspective", School of Architecture and Planning, Anna University, Chennai 600 025, India. EMail: spsekar@vsnl.com or spsekar@hotmail.com

[16]. Vũ Đức Minh, "Nghiên cứu xây dựng bản đồ 3D tỷ lệ 1:2000 thành phố Vĩnh Yên, tỉnh Vĩnh Phúc", Luận văn Thạc sĩ kỹ thuật, Trường đại học Mỏ - Địa chất, 2013.

[17]. Phạm Thanh Tình, "Nghiên cứu xây dựng mô hình Cyber City phục vụ công tác định hướng quy hoạch không gian" Luận văn Thạc sĩ kỹ thuật, Trường đại học Mỏ Địa chất, 2015.

[18]. Phạm Trọng Mạnh, "Quy hoạch đô thị với việc tiếp cận hệ thống thông tin địa lý (GIS)", Luận án tiến sĩ, Trường đại học Kiến trúc Hà Nội, 1996.

[19]. Vũ Chí Đồng và nnk, "Nghiên cứu áp dụng công nghệ hệ thống thông tin địa lý phục vụ quy hoạch và quản lý xây dựng đô thị”, Báo cáo tổng kết đề tài khoa học cấp Bộ RD54, 2002.

[20]. Vũ Chí Đồng và nnk, "Đổi mới công tác lập đồ án quy hoạch xây dựng từ nghiên cứu ứng dụng công nghệ GIS", Báo cáo tổng kết đề tài khoa học cấp Bộ RD25-07, 2008.

[21]. Lưu Đức Hải, "Thực trạng và giải pháp ứng dụng thông tin địa lý trong phát triển đô thị”, Bộ xây dựng, Hà Nội 2008.

[22]. Nguyễn Quang Minh, "Nghiên cứu xây dựng cơ sở dữ liệu thông tin địa hình 3D phục vụ công tác quy hoạch đô thị nông thôn", Đề tài nghiên cứu khoa học cấp cơ sở, T11-23, Trường đại học Mỏ - Địa chất, 2011.

[23]. Nguyễn Văn Huy, Nguyễn Mạnh Hùng, "Ứng dụng ArcGIS trong công tác xây dựng cơ sở dữ liệu GIS3D Thành phố Vũng Tàu”, Đồ án tốt nghiệp, Trường đại học Mỏ - Địa chất, 2010.

[24]. Nguyễn Danh Đức, Nguyễn Văn Khôi, "Nghiên cứu xây dựng cơ sở dữ liệu GIS3D phục vụ công tác phát triển du lịch khu vực Điện Biên", Đồ án tốt nghiệp, Trường đại học Mỏ - Địa chất, 2011.

[25]. Lê Thị Phương Thảo, "Nghiên cứu và ứng dụng công nghệ GIS trong xây dựng cơ sở dữ liệu 3DGIS phục vụ công tác mô hình hóa bề mặt địa hình từ đó chỉ ra một số ứng dụng trên mô hình 3DGIS", Đồ án tốt nghiệp, Trường đại học Mỏ - Địa chất, 2011.

[26]. Nguyễn Thế Thận, "Giải pháp xây dựng mô hình cảnh quan đô thị ảo 3D bằng phần mềm thông tin địa lý MapsiteGIS", Bộ xây dựng, Hà Nội 2008.

[27]. Bùi Ngọc Quý, "Nghiên cứu ứng dụng ArcScene trong xây dựng cơ sở dưr liệu 3D GIS thành phố Lạng Sơn", Tạp chí Tài nguyên và Môi trường, số 9 , trang 53$55,(9 / 2008) .0$ 